
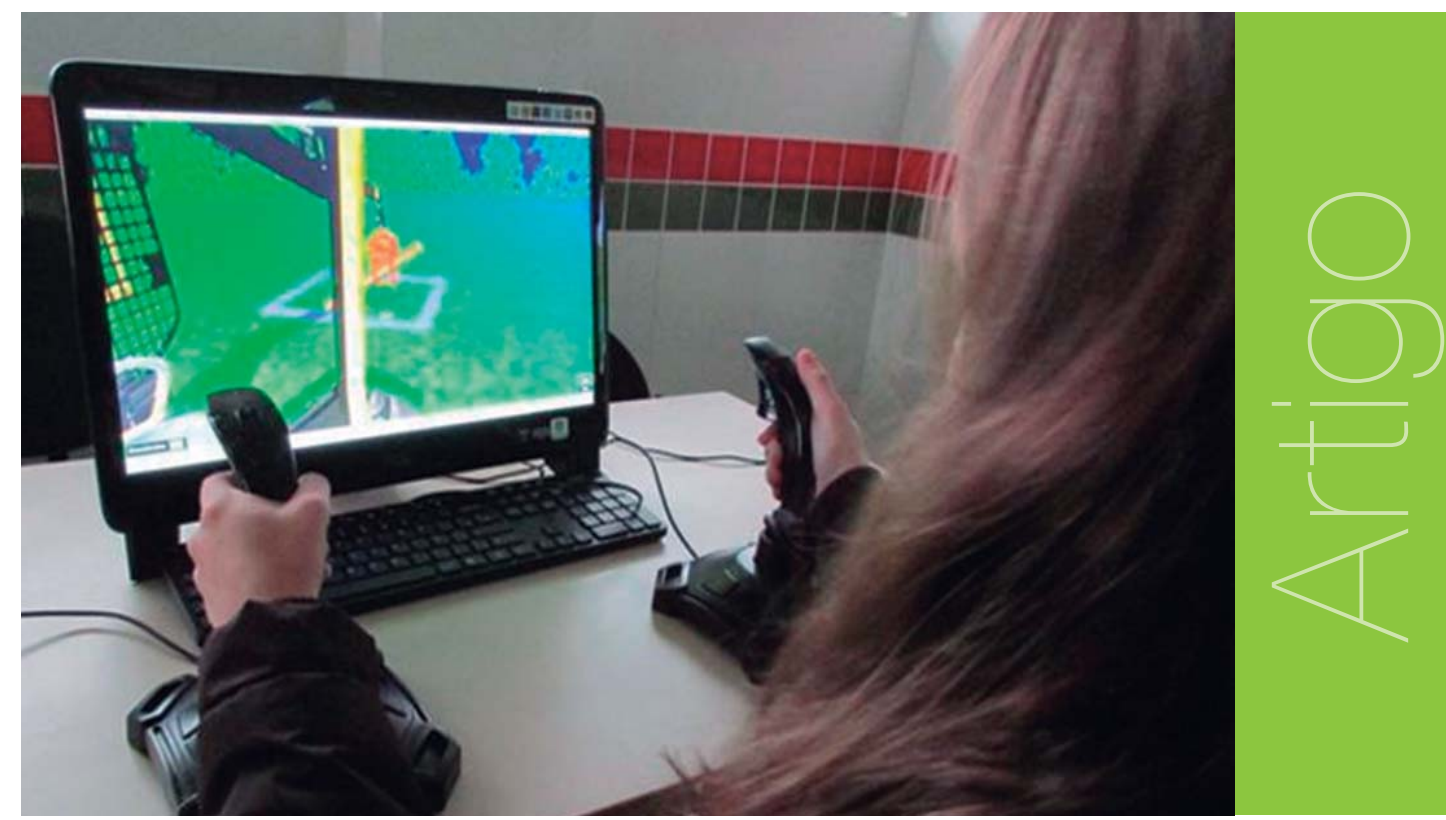

\title{
Desempenho de jovens no uso de simulador de realidade virtual de colheita florestal em cidades paranaenses
}

Débora Martins Mucellini ${ }^{1}$ - deboramucellini@hotmail.com

Renato César Gonçalves Robert ${ }^{2}$ - renatorobert@ufpr.br

\section{RESUMO}

A pesquisa parte do treinamento de estudantes em um simulador de realidade virtual de Harvester, com carga horária de 32 horas nas cidades de Arapoti, Campo do Tenente, Sengés e Tunas do Paraná. 0 objetivo foi criar uma metodologia, que quantificasse a evolução dos alunos nos treinamentos para expressar o desempenho médio de cada local, e assim, relacionar estas notas finais com os Índices de Desenvolvimento Humano dos municípios. Gerou-se uma linha de tendência decorrida das variáveis desempenho médio e IDH. 0 resultado foi que quanto menor o IDH, melhor a execução dos alunos. A cidade mais representativa foi Tunas do Paraná, com desempenho médio de 70,2\%. Esse resultado sugere estar ligado às restritas opções de qualificação profissional dentro de cidades menores, transformando a oportunidade do curso em completa dedicação.

\section{PALAVRAS-CHAVE}

Cidades. Trator Florestal. Estudantes. Avaliação.

\section{ABSTRACT}

The present article aims to expose the extension project "Jornal Comunitário Folha da Princesa", that was created in 2000 and has as target audience the community from Vila Princesa, a

\footnotetext{
1 Estudante de Graduação do Curso de Engenharia Florestal da UFPR.

2 Engenheiro Florestal e Engenheiro de Segurança do Trabalho, UFPR. Professor do Curso de Engenharia Florestal da UFPR.
} 
neighborhood in outskirts of Pelotas. The objective of the newspaper is to share information, free and alternative, portraying the reality of the neighborhood. Serving as a forum for dialogue

\section{KEYWORDS}

Cities. Forest Tractor. Students. Evaluation.

\section{Introdução}

A importância e relevância do setor florestal no Brasil é destaque em diversas áreas. Do ponto de vista econômico, tem sido responsável por aproximadamente $4 \%$ do Produto Interno Bruto (PIB), gerando 680.000 empregos diretos e 1,722 mil empregos indiretos, US\$ 458 milhões em arrecadação de impostos e US\$ 7,7 bilhões em divisas de exportações (ABRAF, 2007). Contribui também para a melhoria da qualidade de vida, através da manutenção dos recursos hídricos, edáficos e da qualidade do ar (SOBRINHO, 1995).

Dentro desse setor, uma das atividades consideradas mais importantes é a colheita florestal, visto ser a mais onerosa em termos de custo de produção e que representa a operação final de um ciclo de produção, na qual são obtidos os produtos mais valiosos, constituindo um dos fatores que determinam a rentabilidade florestal (ARCE et al, 2004). Essa atividade é a que também mais sofre com o processo de mecanização. A colheita florestal representa 50\%, ou mais, do total dos custos finais da madeira posta na indústria (MACHAD0, 1989).

Dentro da colheita florestal, existe o sistema de colheita de toras curtas ou cut - to -lenght, sendo o "Harvester" (Fig. 1) ou o colhedor florestal, o principal trator utilizado na derrubada e processamento das árvores, o que consiste em alguns casos, no descascamento das árvores, no desgalhamento e no corte em toras de comprimento predeterminado (traçamento), deixandose as toras agrupadas e prontas para serem retiradas da área de colheita.

Trata-se de uma máquina autopropelida, constituída por um conjunto motriz de alta mobilidade dentro da floresta e boa estabilidade, um braço hidráulico e um cabeçote processador (AMABILINI, 1991). É composta da unidade de potência (trator), lança telescópica e unidade processadora (SILVEIRA, 2001). É uma máquina que pode executar, simultaneamente, as operações de derrubada, desgalhamento, descascamento, traçamento e empilhamento da madeira (MACHAD0, 2002).

Sobre o treinamento de operadores para a máquina Harvester, Parise e Malinovski (2002) afirmam que a metodologia mais utilizada tem sido a combinação de treinamentos teóricos e práticos diretamente nas máquinas e equipamentos. Entretanto, a utilização dos próprios equipamentos no processo de treinamento nem sempre é viável, em razão dos elevados custos ocasionados pela mobilização das máquinas e equipamentos, os riscos de acidentes, a maior possibilidade de quebras dos equipamentos e as expectativas imediatas dos resultados de produção. Por isso, segundo Lacerda e Mazon (2002), a metodologia mais eficiente de treinamento disponível é 0 simulador de realidade virtual, proporcionando a capacitação de futuros operadores de forma rápida, eficiente e com baixos custos, além de evitar os acidentes, mobilização e quebra dos equipamentos (PACKALÉN, 2001).

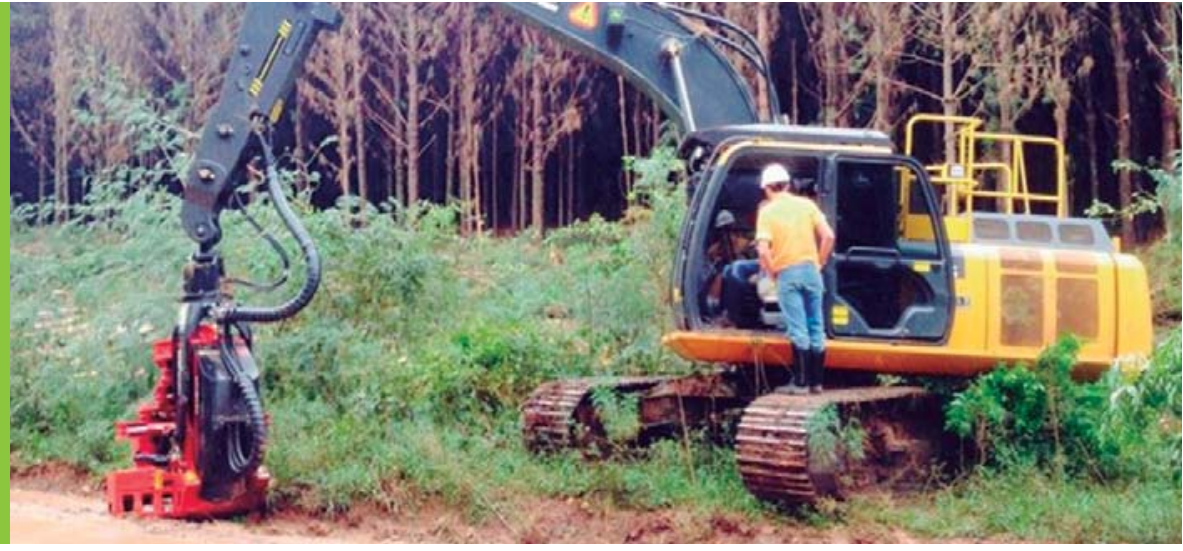


0 projeto de extensão aqui apresentado foi intitulado de "Colheita Florestal Para Jovens" realizado pelo Laboratório de Abastecimento e Mecanização Florestal (LAMEC) e a Pró- Reitoria de Extensão e Cultura (PROEC), ambos da UFPR, juntamente com empresas parceiras e escolas municipais.

0 foco principal do projeto é motivar jovens residentes em cidades onde o setor florestal é predominantemente desenvolvido a buscarem opções de trabalho na área florestal, sendo uma delas a operação de tratores florestais de alta tecnologia como o Harvester, já que existe uma demanda crescente por profissionais e qualificação profissional nestas regiões. Trata-se, portanto, de despertar o interesse de jovens pelo ramo florestal não só a partir do treinamento desses alunos em um simulador de realidade virtual, chamado SIMLOG (que simula operações de derrubada, empilhamento e processamento de toras dentro de uma área), mas como também os estimular pela visualização prática das operações em campo que uma visita técnica pode trazer.

Dessa forma, o projeto instiga os estudantes a traçarem um planejamento profissional, mostrando caminhos para o seu aperfeiçoamento e qualificação futura.

As instruções teóricas e práticas foram realizadas por intermédio de bolsistas estudantes de engenharia florestal, engenharia mecânica e psicologia, o que permitiu entre a equipe, a interdisciplinaridade e a troca de informações de diferentes áreas do conhecimento, além da detecção do que necessita ser aperfeiçoado com base nos resultados obtidos em cada cidade.

0 objetivo do trabalho foi analisar a correlação entre as cidades onde os jovens obtiveram maior desempenho nas operações do simulador e os seus Índices de Desenvolvimento Humano.

\section{Metodologia}

\section{1 Área de Estudo}

0 trabalho foi conduzido pelos bolsistas de extensão do Laboratório de Abastecimento e Mecanização Florestal da Universidade Federal do Paraná (UFPR) em quatro cidades: Arapoti, Campo do Tenente, Sengés e Tunas do Paraná.

\subsection{População e Amostragem}

0 projeto ocorreu no período de Junho a Outubro de 2013, contando com a participação de 33 alunos do ensino médio. A carga horária total de cada curso contou com 32 horas em cada cidade, que incluiu uma apresentação sobre o setor florestal, visita técnica as áreas de colheita da empresa (Fig. 2) e treinamento efetivo no simulador de realidade virtual.

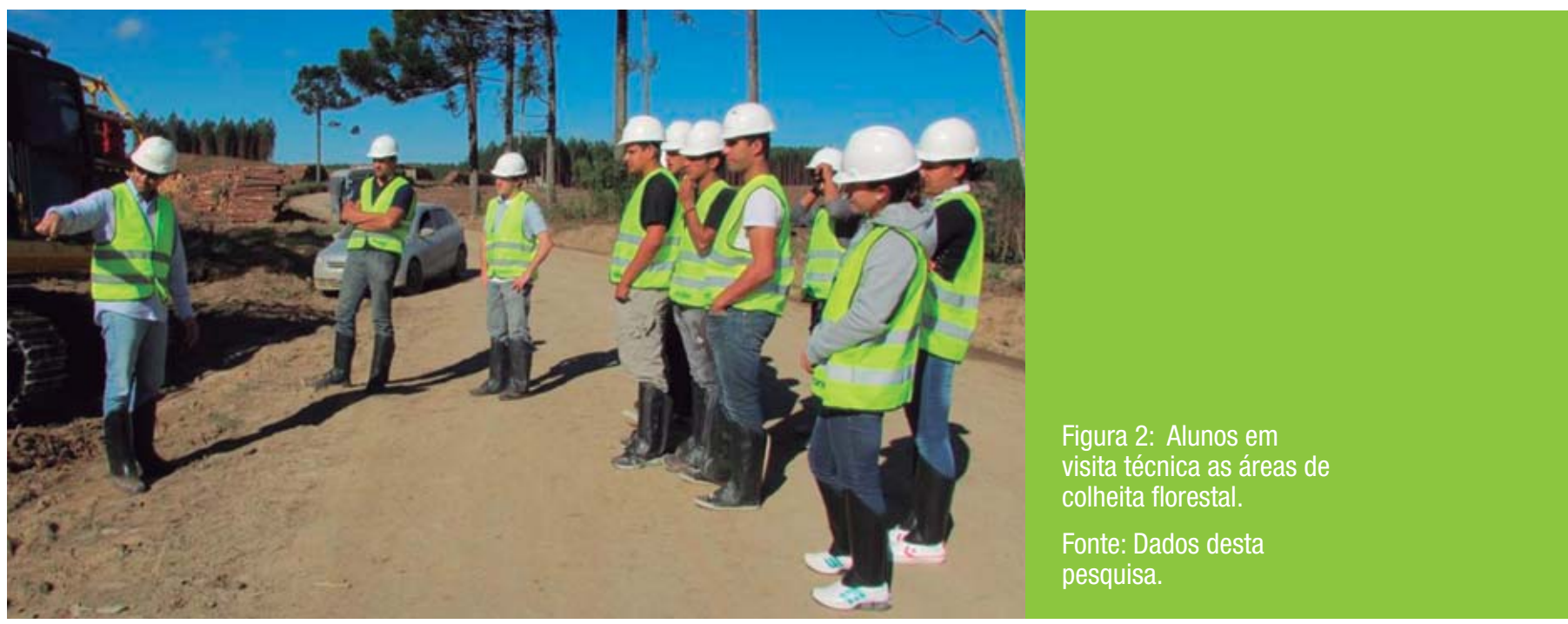




\subsection{Equipamentos Utilizados}

Na realização do curso foi utilizado o software de simulação de realidade virtual de Harvester, Simulation Launcher (SIMLOG), acompanhado de quatro máquinas: dois computadores (CPU e monitor com tela de 15"), um monitor LCD de 42", e um telão para projeção multimídia, combinado a uma poltrona de trator com dois joysticks acoplados aos braços. Para o controle dos movimentos e execução das atividades, todas as unidades de simulação contaram com 2 joysticks do tipo attack 3 .

Figura 3: Aluna utilizando o SIMLOG.

Fonte: Dados desta pesquisa.

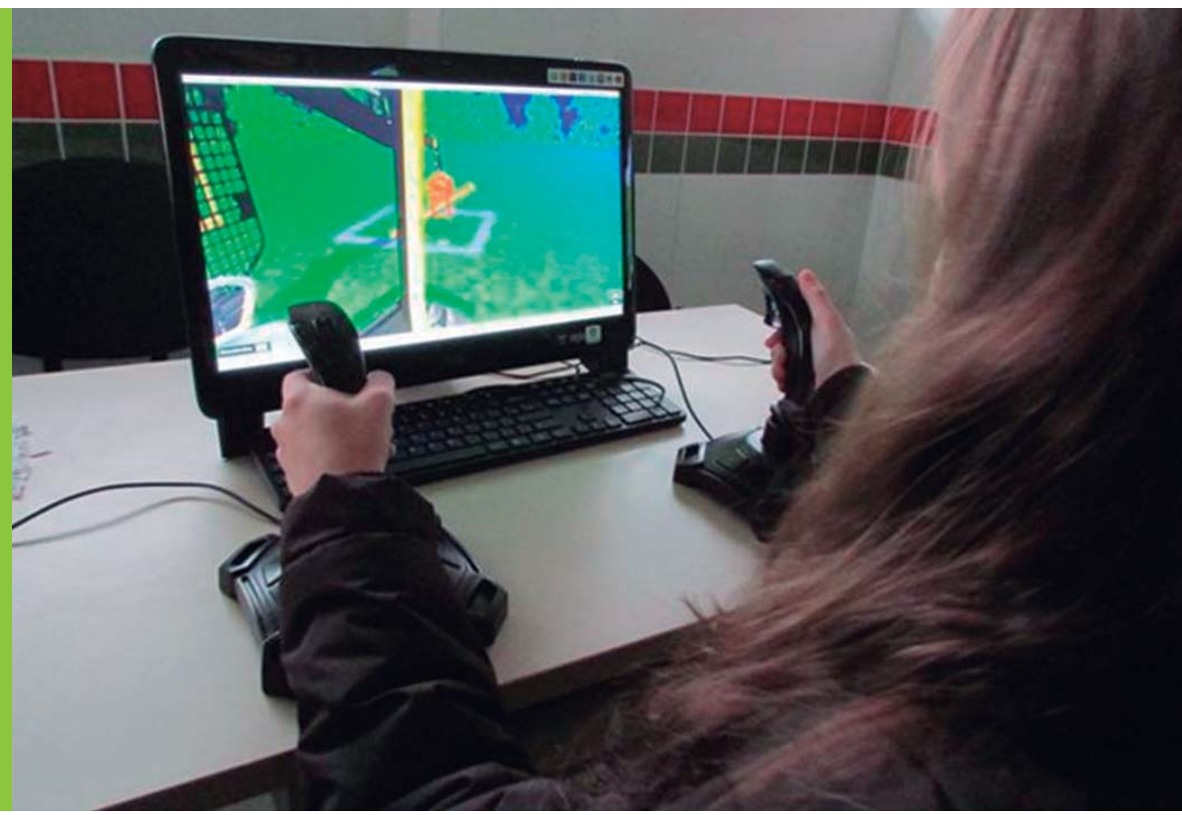

\subsection{Coleta e Análise de Dados}

0 software SIMLOG conta com oito módulos de simulação, citados no Quadro 1:

Fonte: Adaptado
de LOPES et al., (2008)
Quadro 1: Módulos de
simulação do software
SIMLG.

\begin{tabular}{|c|c|c|}
\hline Módulo 1 & Comandos do cabeçote & $\begin{array}{l}\text { Aprendizado dos comandos básicos } \\
\text { de operação no simulador. }\end{array}$ \\
\hline Módulo 2 & $\begin{array}{l}\text { Execução da direção } \\
\text { de queda }\end{array}$ & $\begin{array}{l}\text { Realiza apenas o direcionamento de queda } \\
\text { da árvore e o controle da altura de toco. }\end{array}$ \\
\hline Módulo 3 & $\begin{array}{l}\text { Execução de } \\
\text { derrubada simples }\end{array}$ & $\begin{array}{l}\text { Executa a derrubada de uma única árvore, } \\
\text { controlando apenas a direção de queda. }\end{array}$ \\
\hline Módulo 4 & $\begin{array}{l}\text { Execução de } \\
\text { derrubada simples } \\
\text { com processamento }\end{array}$ & $\begin{array}{l}\text { Efetua a derrubada direcional e processamento } \\
\text { de uma árvore, controlando a altura de toco } \\
\text { e comprimento da tora manualmente. }\end{array}$ \\
\hline Módulo 5 & $\begin{array}{l}\text { Execução de derrubada } \\
\text { simples e empilhamento }\end{array}$ & $\begin{array}{l}\text { Realiza a derrubada, processamento e } \\
\text { empilhamento da árvore em áreas específicas. }\end{array}$ \\
\hline Módulo 6 & $\begin{array}{l}\text { Execução de derrubada } \\
\text { múltipla e empilhamento }\end{array}$ & $\begin{array}{l}\text { Executa a derrubada e processamento de mais } \\
\text { de uma árvore, controlando os comprimentos da } \\
\text { tora e empilhando-as nas áreas específicas. }\end{array}$ \\
\hline Módulo 7 & Processamento & $\begin{array}{l}\text { Executa o processamento das árvores } \\
\text { dispostas na beira do talhão, empilhando } \\
\text { as toras em áreas específicas. }\end{array}$ \\
\hline Módulo 8 & $\begin{array}{l}\text { Movimentação da } \\
\text { máquina, derrubada } \\
\text { e processamento }\end{array}$ & $\begin{array}{l}\text { Para alcançar a árvore, as esteiras do maquinário } \\
\text { devem ser movimentadas, e posteriormente as etapas } \\
\text { de derrubada e processamento são realizadas. }\end{array}$ \\
\hline
\end{tabular}


0 primeiro módulo foi desconsiderado na avaliação por se tratar apenas da identificação básica dos comandos da máquina virtual.

Quanto à coleta de dados, cada módulo apresenta uma quantidade de variáveis (Quadro 2), existindo um ciclo a ser concluído. Sendo assim, foi estipulado um número fixo de ciclos a serem concluídos por módulo, onde os módulos 1 e 2 tiveram 15 ciclos, módulos 4 e 5 tiveram 10 ciclos e os módulos 6, 7 e 8 tiveram 5 ciclos. Todo esse processo foi repetido duas vezes, denominando a primeira repetição de bloco 1, e a segunda repetição de bloco 2.

A execução de todos os módulos foi cronometrada, sendo que para cada etapa de simulação os estudantes tiveram 10 minutos livres para treino e adaptação ao exercício e 10 minutos para marcação efetiva dos dados gerados no simulador.

\subsection{Variáveis Analisadas}

Os valores de todas as variáveis existentes no simulador foram registrados pelos alunos, para que a evolução de cada região fosse avaliada, e como resultado dessas informações, foi calculada a média aritmética dos blocos 1 e 2.

\begin{tabular}{|c|c|c|c|c|c|c|c|c|}
\hline \multirow{2}{*}{ Variável } & \multirow{2}{*}{ Descrição } & \multicolumn{7}{|c|}{ Módulos } \\
\hline & & 2 & 3 & 4 & 5 & 6 & 7 & 8 \\
\hline $\begin{array}{l}\text { Tempo } \\
\text { (s) }\end{array}$ & $\begin{array}{l}\text { Representa o tempo de execução, em } \\
\text { segundos, que demora para o operador finalizar } \\
\text { um ciclo de acordo com cada módulo. }\end{array}$ & $x$ & $x$ & $x$ & $\mathbf{x}$ & $x$ & $x$ & $x$ \\
\hline $\begin{array}{l}\text { Erro de } \\
\text { Orientação } \\
\text { (graus) }\end{array}$ & $\begin{array}{l}\text { Mede o erro de orientação de acordo com } \\
\text { uma direção de queda estabelecida. }\end{array}$ & $x$ & $x$ & & & & & \\
\hline $\begin{array}{l}\text { Erro em Altura } \\
(\mathrm{cm})\end{array}$ & $\begin{array}{l}\text { Representa o erro cometido no momento } \\
\text { do corte, em relação a altura estipulada. }\end{array}$ & $x$ & & & & & & \\
\hline $\begin{array}{l}\text { Altura de Toco } \\
(\mathrm{cm})\end{array}$ & $\begin{array}{l}\text { Representa a altura em que é feito } \\
\text { o corte, em relação ao solo. }\end{array}$ & & $x$ & $x$ & $x$ & $x$ & & $x$ \\
\hline $\begin{array}{l}\text { Erro } \\
\text { Comprimento } \\
\text { (cm) }\end{array}$ & $\begin{array}{l}\text { Expõe o erro de comprimento ligado } \\
\text { ao processamento das toras. }\end{array}$ & & & $x$ & $\mathbf{x}$ & $x$ & $x$ & $x$ \\
\hline $\begin{array}{l}\text { Altura } \\
\text { Processamento } \\
\text { (cm) }\end{array}$ & $\begin{array}{l}\text { Representa a altura em relação ao nível do } \\
\text { solo em que ocorre o processamento. }\end{array}$ & & & $x$ & $\mathbf{x}$ & $x$ & $x$ & $x$ \\
\hline $\begin{array}{l}\text { Processamento } \\
(\%)\end{array}$ & $\begin{array}{l}\text { Mede em porcentagem as árvores } \\
\text { efetivamente processadas durante os ciclos. }\end{array}$ & & & $x$ & $\mathbf{x}$ & $x$ & $x$ & $x$ \\
\hline $\begin{array}{l}\text { Empilhamento } \\
(\%)\end{array}$ & $\begin{array}{l}\text { Mede a quantidade de toras depostas } \\
\text { dentro da área de empilhamento. }\end{array}$ & & & & $\mathbf{x}$ & $x$ & $x$ & $x$ \\
\hline $\begin{array}{l}\text { Produtividade } \\
\text { (m3/h) }\end{array}$ & $\begin{array}{l}\text { Fornece o desempenho efetivo } \\
\text { e eficácia na operação. }\end{array}$ & & & & & $x$ & $x$ & \\
\hline
\end{tabular}

0 próximo passo foi descobrir, utilizando os resultados da etapa anterior, a evolução que essas cidades obtiveram entre o primeiro e o segundo bloco de repetição. Para isso, foi utilizada uma fórmula para calcular o ganho adquirido em desempenho médio, expresso na seguinte equação:

$$
g \%=\left(1-\left(\frac{m 2}{m 1}\right)\right) * 100
$$


Em que, $g(\%)=$ Ganho porcentual em relação ao início do treinamento na respectiva variável e módulo, m2 = Média no final do módulo e m1 = Média no início do módulo (LOPES et al, 2008).

Como o objetivo principal é comparar o desempenho dos alunos, separados por cidades, em relação ao Índice de Desenvolvimento Humano (IDH), foi preciso compilar todos os dados de ganhos de desempenho médio em um só, da seguinte forma:

a) Para cada variável, foi estabelecida uma nota de zero a cem;

Essa nota obtida foi proveniente de uma relação entre o ganho máximo e mínimo, ou seja, entre a cidade que teve um maior desempenho, e a cidade com um menor desempenho, onde zero correspondeu ao ganho mínimo e cem ao ganho máximo.

b) Com a nota de todas as variáveis descobertas, fez-se uma média aritmética por módulo;

c) Por fim, o valor final de cada cidade foi resultante de uma média da nota dos sete módulos avaliados.

As informações pertinentes ao IDH, que permitem a efetiva associação entre as cidades estudadas, estão listadas na Tabela 1.

Tabela 1: Classificação das cidades, segundo Índice de Desenvolvimento Humano. Fonte: PNUD Brasil (2013).

\begin{tabular}{lccc}
\hline Cidade & IDH & Classificação & População \\
\hline Arapoti & 0,723 & Alto & 25.855 \\
\hline Campo do Tenente & 0,686 & Médio & 7.125 \\
\hline Sengés & 0,663 & Médio & 18.414 \\
\hline Tunas do Paraná & 0,610 & Médio & 6.256
\end{tabular}

A escala de classificação adotada pelo Programa das Nações Unidas para o Desenvolvimento (PNUD), responsável pelo cálculo de IDH, que avalia renda, longevidade e educação, é apresentada na Tabela 2.

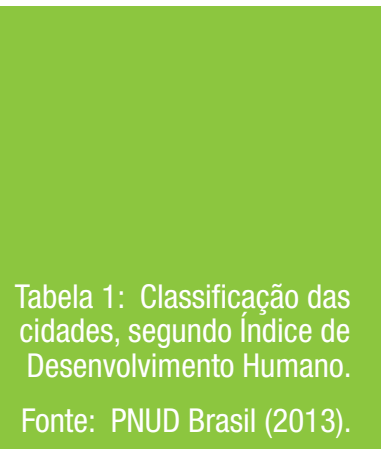

\begin{tabular}{cc} 
& Classificação IDH \\
\hline Muito Alto: & $0,800-1,000$ \\
\hline Alto: & $0,700-0,799$ \\
\hline Médio: & $0,600-0,699$ \\
\hline Baixo: & $0,500-0,599$ \\
\hline Muito Baixo: & $0,000-0,499$ \\
\hline
\end{tabular}




\begin{tabular}{|c|c|c|c|c|c|c|c|c|c|c|}
\hline \multicolumn{11}{|c|}{ TUNAS DO PARANÁ PR } \\
\hline Módulo & Tempo & $\begin{array}{l}\text { Erro } \\
\text { Orient. }\end{array}$ & $\begin{array}{l}\text { Erro } \\
\text { Alt. }\end{array}$ & $\begin{array}{l}\text { Alt. } \\
\text { Toco }\end{array}$ & $\begin{array}{l}\text { Erro } \\
\text { Comp. }\end{array}$ & $\begin{array}{c}\text { Alt. } \\
\text { Process. }\end{array}$ & Process. & Empilh. & Produt. & Média \\
\hline 2 & 100,0 & 54,8 & 0,0 & - & - & - & - & - & - & 51,6 \\
\hline 3 & 100,0 & 100,0 & - & 100,0 & - & - & - & - & - & 100,0 \\
\hline 4 & 98,0 & - & - & 100,0 & 100,0 & 44,3 & 100,0 & - & - & 88,5 \\
\hline 5 & 100,0 & - & - & 96,4 & 0,0 & 100,0 & 100,0 & 19,8 & - & 69,4 \\
\hline 6 & 100,0 & - & - & 0,0 & 46,4 & 60,0 & 43,0 & 0,0 & 90,6 & 48,6 \\
\hline 7 & 100,0 & - & - & - & 0,0 & 23,9 & 31,3 & 100,0 & 100,0 & 59,2 \\
\hline 8 & 100,0 & - & - & 100,0 & 45,6 & 0,0 & 100,0 & 100,0 & - & 74,3 \\
\hline \multicolumn{11}{|c|}{ ARAPOTI PR } \\
\hline Módulo & Tempo & $\begin{array}{c}\text { Erro } \\
\text { Orient. }\end{array}$ & $\begin{array}{l}\text { Erro } \\
\text { Alt. }\end{array}$ & $\begin{array}{l}\text { Alt. } \\
\text { Toco }\end{array}$ & $\begin{array}{c}\text { Erro } \\
\text { Comp. }\end{array}$ & $\begin{array}{c}\text { Alt. } \\
\text { Process. }\end{array}$ & Process. & Empilh. & Produt. & Média \\
\hline 2 & 26,1 & 100,0 & 84,7 & - & - & - & - & - & - & 70,3 \\
\hline 3 & 93,9 & 41,2 & - & 0,0 & - & - & - & - & - & 45,0 \\
\hline 4 & 100,0 & - & - & 0,0 & 85,3 & 0,0 & 96,2 & - & - & 56,3 \\
\hline 5 & 34,6 & - & - & 0,0 & 92,8 & 95,9 & 0,0 & 0,0 & - & 37,2 \\
\hline 6 & 22,1 & - & - & 44,7 & 95,9 & 10,7 & 100,0 & 100,0 & 100,0 & 67,6 \\
\hline 7 & 12,0 & - & - & - & 15,5 & 79,2 & 0,0 & 17,7 & 60,1 & 30,8 \\
\hline 8 & 7,6 & - & - & 42,3 & 12,4 & 71,1 & 0,7 & 0,0 & - & 22,3 \\
\hline \multicolumn{11}{|c|}{ CAMPO DO TENENTE PR } \\
\hline Módulo & Tempo & $\begin{array}{c}\text { Erro } \\
\text { Orient. }\end{array}$ & $\begin{array}{l}\text { Erro } \\
\text { Alt. }\end{array}$ & $\begin{array}{l}\text { Alt. } \\
\text { Toco }\end{array}$ & $\begin{array}{c}\text { Erro } \\
\text { Comp. }\end{array}$ & $\begin{array}{c}\text { Alt. } \\
\text { Process. }\end{array}$ & Process. & Empilh. & Produt. & Média \\
\hline 2 & 52,9 & 12,4 & 100,0 & - & - & - & - & - & - & 55,1 \\
\hline 3 & 40,2 & 40,6 & - & 55,0 & - & - & - & - & - & 45,2 \\
\hline 4 & 13,6 & - & - & 3,4 & 0,0 & 100,0 & 2,0 & - & - & 23,8 \\
\hline 5 & 36,7 & - & - & 100,0 & 91,7 & 56,5 & 79,7 & 29,5 & - & 65,7 \\
\hline 6 & 30,3 & - & - & 2,0 & 100,0 & 100,0 & 64,5 & 16,2 & 22,7 & 48,0 \\
\hline 7 & 54,8 & - & - & - & 39,4 & 100,0 & 100,0 & 8,1 & 55,1 & 59,6 \\
\hline 8 & 0,0 & - & - & 32,4 & 100,0 & 100,0 & 0,0 & 92,1 & - & 54,1 \\
\hline \multicolumn{11}{|c|}{ SENGÉS PR } \\
\hline Módulo & Tempo & $\begin{array}{c}\text { Erro } \\
\text { Orient. }\end{array}$ & $\begin{array}{l}\text { Erro } \\
\text { Alt. }\end{array}$ & $\begin{array}{l}\text { Alt. } \\
\text { Toco }\end{array}$ & $\begin{array}{c}\text { Erro } \\
\text { Comp. }\end{array}$ & $\begin{array}{c}\text { Alt. } \\
\text { Process. }\end{array}$ & Process. & Empilh. & Produt. & Média \\
\hline 2 & 0,0 & 0,0 & 94,1 & - & - & - & - & - & - & 31,4 \\
\hline 3 & 0,0 & 0,0 & - & 71,0 & - & - & - & - & - & 23,7 \\
\hline 4 & 0,0 & - & - & 11,1 & 25,3 & 94,1 & 0,0 & - & - & 26,1 \\
\hline 5 & 0,0 & - & - & 79,5 & 100,0 & 0,0 & 35,0 & 100,0 & - & 52,4 \\
\hline 6 & 0,0 & - & - & 100,0 & 0,0 & 0,0 & 0,0 & 43,1 & 0,0 & 20,4 \\
\hline 7 & 0,0 & - & - & - & 100,0 & 0,0 & 16,8 & 0,0 & 0,0 & 19,5 \\
\hline 8 & 32,9 & - & - & 0,0 & 0,0 & 55,8 & 65,7 & 96,7 & - & 41,8 \\
\hline
\end{tabular}

Tabela 3: Ganho adquirido em porcentagem (\%) sobre 0 desempenho médio.

Fonte: Dados desta pesquisa.

A média aritmética feita em cada módulo considerou que toda variável estudada tem igual valor de importância no processo final de avaliação do desempenho dos alunos. Sendo assim, a nota final (Tab. 4) foi a compilação das notas das etapas de simulação efetuadas.

Essa nota que leva o nome de desempenho médio em porcentagem, aliada aos valores fixos de IDH, resultou em uma tabela final de resultados: 
Tabela 4: Desempenho final das cidades.

Fonte: PNUD Brasil (2013) e dados desta pesquisa.

\begin{tabular}{ccc} 
Cidade & IDH & $\begin{array}{c}\text { Desempenho Médio } \\
(\%)\end{array}$ \\
\hline Arapoti & 0,723 & 47,1 \\
\hline Campo do Tenente & 0,686 & 50,2 \\
\hline Sengés & 0,663 & 30,8 \\
\hline Tunas do Paraná & 0,610 & 70,2 \\
\hline
\end{tabular}

A partir desta análise, foi possível criar um gráfico com as variáveis IDH e Desempenho Médio das quatro cidades estudadas, e nele elaborar uma linha de tendência.

Gráfico 1: Desempenho final das cidades, seguido de linha de tendência.

Fonte: PNUD Brasil (2013) e dados desta pesquisa.

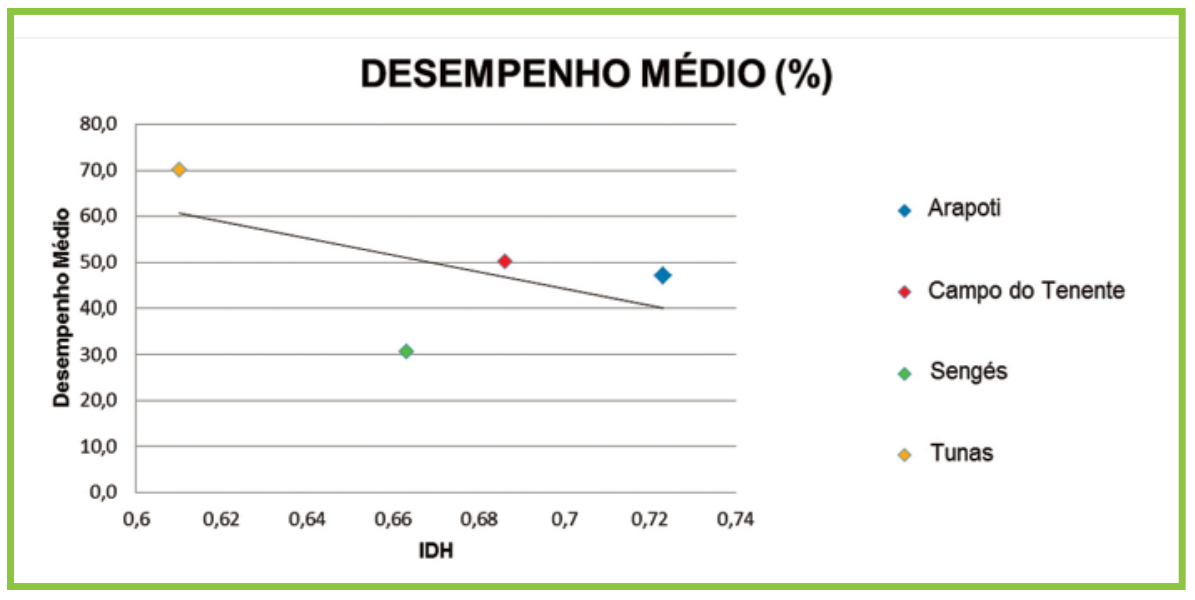

Segundo Nascimento et al. (2012) o treinamento dos operadores com o uso do simulador de realidade virtual para corte florestal é eficiente e demonstra que tanto 0 trabalho masculino como feminino são recomendados para a atividade de colheita mecanizada com a utilização de Harvester. Desta forma, não foi necessário avaliar os alunos em importância de gêneros.

Tunas do Paraná se destacou por apresentar o melhor resultado quanto ao desempenho médio obtido. Enquanto isso, Sengés obteve a menor avaliação.

Ao integrar a nota de desempenho médio e o IDH de cada cidade, foi possível criar uma curva de tendência entre os resultados, da qual percebeu que quanto menor o IDH, maior era o desempenho médio obtido, mostrando assim, que existe uma relação entre a eficiência dos alunos quanto a sua evolução no simulador de realidade virtual SIMLOG e o Índice de Desenvolvimento Humano.

Conforme publicado em PNUD Brasil (2013), pequenas cidades não necessariamente apresentam baixo IDH. Desta forma, o aprimoramento do estudo seria relevante.

\section{Conclusões}

A partir dos dados provenientes do projeto, identificou-se que os estudantes que mais aumentaram sua eficiência no simulador de realidade virtual, proveniente da comparação entre os dois blocos de repetição, na qual se criou a variável desempenho médio, foram da cidade de Tunas do Paraná. Enquanto isso, Sengés foi a cidade com menor desempenho na avaliação.

A linha de tendência criada mostrou que o desempenho médio é inversamente proporcional ao IDH, ou seja, quanto menor o IDH da cidade, maior o ganho adquirido no que tange 0 desempenho no simulador de realidade virtual SIMLOG. 
Subentende-se com essa afirmação, que estes jovens apresentam um comportamento diferente dos que estão presentes em ambientes com IDH mais elevado. Este fato pode estar ligado às restritas opções de qualificação dentro de uma cidade pequena, transformando a oportunidade do curso em completa dedicação.

\section{Referências}

ABRAF. Anuário Estatístico da ABRAF. Ano base 2006. Brasília: ABRAF, 2007.

AMABILINI, V. D. Utilização do Harvester na exploração florestal. 1. Belo Horizonte: Simpósio brasileiro sobre exploração e transporte florestal, 1991.

ARCE, Julio Eduardo; MACDONAGH, Patricio; FRIEDL, Ramón Alejandro. Geração de padrões ótimos de corte através de algoritmos de traçamento aplicados a fiastes individuais. V.28, n.2. Viçosa: Revista Árvore, 2004.

LACERDA, J. F. S. B.; MAZON, A. Uso de simulador de realidade virtual no treinamento de operadores da colheita florestal. XII. Curitiba: Seminário de atualização sobre sistemas de colheita de madeira e transporte florestal, 2002.

LOPES, Eduardo et al. Avaliação do treinamento de operadores de Harvester com uso de simulador de realidade virtual. V. 32, n. 2, p.291-298. Viçosa: Revista Árvore, 2008.

MACHADO, Carlos Cardoso. Exploração florestal. 6. Viçosa: Universidade Federal de Viçosa, Imprensa Universitária, 1989.

MACHADO, Carlos Cardoso. 0 setor florestal brasileiro. Viçosa: Colheita Florestal UFV, 2002.

NASCIMENTO, Kaue et al. Avaliação entre gêneros no treinamento com o uso de simulador de realidade virtual para $\mathbf{0}$ corte florestal. V.8, n.15. Goiânia: Enciclopédia Biosfera, 2012.

PACKALÉN, A. Swedish study on Harvester Simulator training: costs cut, quality maintained. N.3. [S.I.]: International Forestry Magazine, Timberjack News, 2001.

PARISE, D. J.; MALINOVSKI, J. R. Análise e reflexões sobre o desenvolvimento tecnológico da colheita florestal no Brasil. XII. Curitiba: Seminário de atualização sobre sistemas de colheita de madeira e transporte florestal, 2002.

PNUD Brasil. 0 que é IDH? Disponível em: <> http://www.pnud.org.br. Acesso em: 25 jan. 2014.

PNUD Brasil; IPEA; FJP. Atlas do desenvolvimento humano no Brasil 2013. Disponível em: <> http://atlasbrasil.org.br/2013/pt/consulta/. Acesso em: 20 jan. 2014.

SILVEIRA, G. M. da. Os cuidados com o trator. Série Mecanização, 1. Viçosa: Aprenda Fácil, 2001.

SOBRINHO, V.F. A importância do Brasil no mercado internacional de madeira e derivados. N.2. Salvador: In. Simpósio Brasileiro sobre transporte florestal, 1995. 